\title{
Forskolin's Effect on Transient K Current in Nudibranch Neurons Is Not Reproduced by cAMP
}

\author{
Julie Coombs and Stuart Thompson \\ Hopkins Marine Station, Stanford University, Pacific Grove, California 93950
}

Forskolin, a diterpene extracted from Coleus forskolii, stimulates the production of CAMP in a variety of cells and is potentially an important tool for studying the role of cAMP in the modulation of neuronal excitability. We studied the effects of forskolin on neurons of nudibranch molluscs and found that it caused characteristic, reversible changes in the amplitude and waveform of the transient $K$ current, $I_{A}$, and also activated an inward current similar to the CAMP. dependent inward current previously described in molluscan neurons. Forskolin altered the time course of $I_{A}$ activation and inactivation but did not affect the voltage dependence or the reversal potential of the current. $I_{A}$ normally inactivates exponentially, but in forskolin the time course of inactivation can be fit by the sum of 2 exponentials with an initial rate that is faster than the control and a final rate that is much slower. On depolarization in forskolin, $I_{A}$ begins to activate at the normal rate, but a slower component of activation is also seen. The changes in $I_{A}$ in the nudibranch cells were qualitatively different than the changes caused by forskolin in Aplysia bag cell neurons (Strong, 1984).

Experiments were performed to determine whether these effects of forskolin require CAMP. Intracellular injection of CAMP, application of membrane-permeable analogs of CAMP, application of phosphodiesterase inhibitors, and intracellular injection of the active catalytic subunit of cAMPdependent protein kinase did not affect the amplitude or waveform of $I_{A}$. Also, the changes in $I_{A}$ that are caused by forskolin were not prevented or reversed by intracellular injection of an inhibitor of CAMP-dependent protein kinase. Cyclic AMP did, however, activate inward current at voltages near the resting potential. We conclude that the changes in $I_{A}$ and the activation of inward current represent separate affects of forskolin. The inward current appears to depend on an increase in intracellular CAMP, while the changes in $J_{A}$ do not. These experiments show that, in addition to activating adenylate cyclase, forskolin may have a separate direct affect on the transient $K$ current.

Cyclic AMP can modulate the excitability of several kinds of neuronal and muscle cells (Kennedy, 1983; Nestler and Greengard, 1983, 1984; Siegelbaum and Tsien, 1983). It is generally

\footnotetext{
Received Mar. 10, 1986; revised July 7, 1986; accepted Aug. 8, 1986.

We thank J. Strong, J. Kauer, and L. Kaczmarek for sharing preprints of their work, W. F. Gilly for sharing his unpublished observations on squid axons, and R. Aldrich for helpful discussions. Todd Scheuer helped with computer programming. We are indebted to P. Sorter of Hoffmann-LaRoche Inc. for the gift of RO20 1724, and I. Levitan for the gift of protein kinase subunit. The research was conducted at the Hopkins Marine Station, and we thank the staff of that institution for their support. Work supported by USPHS Grant NS 14514 to S.T.

Correspondence should be addressed to Stuart Thompson at the above address.

Copyright (C) 1987 Society for Neuroscience $0270-6474 / 87 / 020443-10 \$ 02.00 / 0$
}

thought that this occurs because cAMP, acting as a second messenger, activates protein kinases that phosphorylate ion channels and change their characteristics (Ewald et al., 1985; Shuster et al., 1985). It has been reported that in molluscan neurons an increase in the intracellular concentration of cAMP can modify voltage-dependent $\mathrm{K}$ currents that contribute to spiking activity (Castelluci et al., 1980; DePeyer et al., 1982; Alkon et al., 1983; Kaczmarek and Strumwasser, 1984) and ionic currents that are active at subthreshold voltages and influence the repetitive firing characteristics of the neurons (Drummond et al., 1980; Pellmar, 1981; Deterre et al., 1982; Siegelbaum et al., 1982; Aldenhoff et al., 1983; Green and Gillette, 1983; Connor and Hockberger, 1984).

Forskolin, a lipid soluble diterpene, is potentially an important tool for studying the modulation of ionic currents by cAMP because it stimulates adenylate cyclase in a variety of cells, including molluscan neurons (Seamon and Daly, 1981; Seamon et al., 1981; Deterre et al., 1982; Kauer and Kaczmarek, 1985). It has been suggested that forskolin might be useful in identifying cAMP as a necessary intermediate in the modulation of electrical excitability by neurotransmitters or hormones (Ram, 1983). Deterre et al. (1982) showed that both forskolin and cAMP injection depress a $\mathrm{K}$ current in Helix neurons. Voltage-clamp studies of the transient $\mathrm{K}$ current, $I_{A}$, and the voltage-dependent delayed $\mathrm{K}$ current, $I_{K}$, in neuroendocrine cells of Aplysia showed that forskolin and cAMP modify these currents in similar ways (Strong, 1984; Strong and Kaczmarek, 1986). The use of forskolin to detcrmine whether cAMP is involved in the modulation of ionic currents was called into question, however, by the experiments of Connor and Hockberger (1984), who found that forskolin did not activate the cAMP-dependent Na current in certain nudibranch neurons. The increasing use of forskolin as a pharmacological agent to change the intracellular concentration of cAMP in intact cells makes it important to determine whether forskolin acts specifically on adenylate cyclase or whether it might have additional, unrelated effects on membrane ionic currents.

We studied the effects of forskolin on the transient $\mathrm{K}$ current, $I_{A}$, in neurons of dorid nudibranches. Forskolin reversibly decreased the amplitude of $I_{A}$ and caused characteristic changes in the kinetics of $I_{A}$ activation and inactivation. In some experiments, forskolin also activated an inward current at the resting potential. Cyclic AMP activated the inward current but did not change the amplitude or waveform of $I_{A}$. External application of phosphodiesterase inhibitors (IBMX and RO20 1724) and membrane-permeable analogs of cAMP (dibutyrlcAMP, clorophenylthio-cAMP, and 8-bromo-cAMP), intracellular injection of CAMP, and intracellular injection of the catalytic subunit of CAMP-dependent protein kinase did not reproduce the effect of forskolin on $I_{A}$. The changes in $I_{A}$ that 


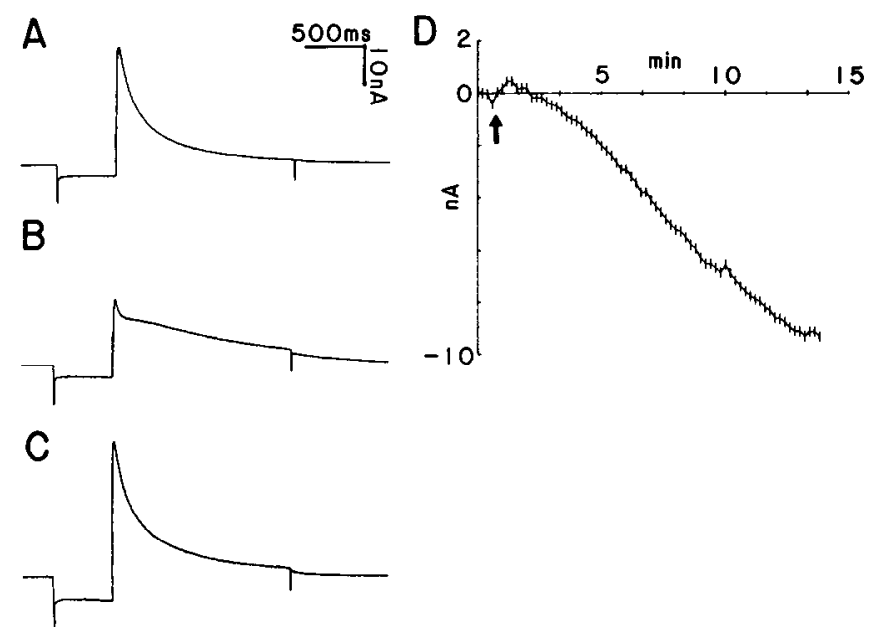

Figure 1. Effect of forskolin on $I_{A}$ and on holding current. The cell was held at $-40 \mathrm{mV}$ and a $500 \mathrm{msec}$ conditioning pulse to $-90 \mathrm{mV}$ was applied before activating $I_{A}$ with a $1.5 \mathrm{sec}$ pulse to $-30 \mathrm{mV} . A$, Normal saline; $B, 10 \mathrm{~min}$ after adding $100 \mu \mathrm{M}$ forskolin to the bath; $C$, 10 min after washing with normal saline. $D$, Time course of the inward current activated by $100 \mu \mathrm{M}$ forskolin at a holding voltage of $-40 \mathrm{mV}$. Forskolin was added at the arrow. The inward current reached an amplitude of $9 \mathrm{nA}$ and was maintained until forskolin was washed away. Pedal ganglion cell from Anisodoris.

result from forskolin were not prevented or reversed by intracellular injection of an inhibitor of cAMP-dependent protein kinase. These experiments show that the effects of forskolin on $I_{A}$ can be separated from the activation of adenylate cylase and that cAMP does not appear to be a necessary intermediate in the modification of $I_{A}$ by forskolin. Instead, forskolin may directly affect $I_{A}$ to cause changes in activation and inactivation kinetics and a reduction in current amplitude.

\section{Materials and Methods}

Experiments were performed on neuron cell bodies excised from the pedal and pleural ganglia of the dorid nudibranch molluscs Doriopsilla albopunctata, Discodoris sandiegensis, and Anisodoris nobilis using the procedures described by Connor (1977). Specimens were collected in Monterey Bay by scuba divers. The central ganglia were removed and treated with neutral protease (Dispase; Calbiochem) for $1 \mathrm{hr}$ followed by a $2 \mathrm{hr}$ wash in order to loosen the epineural sheath so that it could be dissected away. Small groups of neurons containing 1 or 2 large cell bodies were axotomized by undercutting with iris scissors, removed from the ganglia, and transferred to a recording and perfusion chamber maintained at a tempcrature of $13-17^{\circ} \mathrm{C}$. We concentrated our study on the 3 largest neurons in the pedal ganglia and several large neurons in the posterior of the pleural ganglia. A total of 91 cells was studied.

The 2-microelectrode voltage clamp was described by Barish and Thompson (1983). Microelectrodes were filled with $3 \mathrm{M} \mathrm{KCl}$ and had resistances of 4-8 $\mathrm{M} \Omega$. All other electrodes were $\mathrm{Ag}-\mathrm{AgCl}$ pellets interfacing the bath via saline-agar bridges. Membrane voltage was measured between one of the intracellular electrodes and an electrode in the bath and current was measured with a virtual ground circuit. Records of membrane voltage and current were taken on a strip-chart recorder (Gould/Brush 220) or a laboratory computer (DEC 11/23).

The transient potassium current, $I_{A}$, was studied in isolation from other membrane currents by taking advantage of the fact that $I_{A}$ activates at more negative voltages than the delayed outward current or the inward $\mathrm{Na}$ and Ca currents. Between about -40 and $-20 \mathrm{mV}, I_{A}$ can be activated without significant contamination from these other currents (Adams et al., 1980).

The control saline solution had the following composition: $470 \mathrm{~mm}$ $\mathrm{NaCl}, 10 \mathrm{~mm} \mathrm{KCl}, 10 \mathrm{~mm} \mathrm{CaCl}_{2}, 50 \mathrm{~mm} \mathrm{MgCl}, 10 \mathrm{~mm}$ HEPES (pH
7.6-7.8). Forskolin (Calbiochem) was stored as a $10 \mathrm{~mm}$ stock dissolved in EtOH or dimethyl sulfoxide (DMSO). Stock solutions were added to the bath to a final forskolin concentration of 50-100 $\mu \mathrm{M}$. Control experiments using the carrier media without forskolin showed that the results were not due to exposure to EtOH or DMSO. A water-soluble analog of forskolin (forskolin, 7-diacetyl-7-O-hemisuccinic acid; Pfeuffer and Metzger, 1982) was obtained from Calbiochem. This was dissolved in the normal saline and applied at a concentration of $100 \mu \mathrm{M}$. Three membrane-permeable analogs of cAMP were used; dibutryl-cAMP (Sigma), clorophenylthio-cAMP (Boerhinger-Mannheim), and 8-bromo-cAMP (Sigma). The phosphodiesterase inhibitor isobutylmethylxanthine (IBMX) was from Sigma. A non-xanthine inhibitor of phosphodiesterase, RO20 1724, was provided by Dr. Peter Sorter of Hoffmann-LaRoche Inc. Cyclic AMP (Na and Tris salts), ATP, and the heat-stable inhibitor of CAMP-dependent protcin kinase (1 gm protcin inhibits 0.6 phosphorylating units of cAMP-dependent protein kinase) were from Sigma. The active catalytic subunit of cAMP-dependent protein kinase was obtained from 2 sources; one preparation of the enzyme was provided by Dr. Irwin Levitan, and the other was from Sigma (specific activity: $32 \mathrm{nM}{ }^{32} \mathrm{P} / \mathrm{mg}$ protein $\mathrm{min}$ ). 3,4-Diaminopyridine (DAP) was from Aldrich Chemical Co.

Substances were injected intracellularly from a third microelectrode by pressure (Picospritzer II, General Valve Co.) or electrophoresis using a constant current source. The injection microelectrode contained one of the following solutions: (1) $1 \mathrm{mM}$ cAMP and $760 \mathrm{mM} \mathrm{KCl}$ (pressure injection experiments); (2) $200 \mathrm{mM}$ cAMP in $\mathrm{H}_{2} \mathrm{O}$ (electrophoretic injection experiments); (3) Sigma protein kinase $(0.5 \mathrm{mg} / \mathrm{ml})$ plus $324 \mathrm{~mm}$ DTT, 5 mm ATP, $80 \%$ sucrose, and $19.8 \% \mathrm{~K}$ buffer; (4) Levitan's protein kinasc $(1.25 \mathrm{mg} / \mathrm{ml})$ plus $18.75 \mathrm{~mm} \mathrm{KH}_{2} \mathrm{PO}_{4}, 93.75 \mathrm{mM} \mathrm{KCl}, 0.0625$ mM DTT, 0.0625 EDTA, 70\% glycerol; or (5) protein kinase inhibitor $(30 \mathrm{ng} / \mathrm{ml})$. The volume injected by pressure (pressure pulses of 25-65 psi applied for $40-60 \mathrm{msec}$ ) was estimated by measuring the diameter of the droplet ejected from the electrode into the cytoplasm by eye with a micrometer in the eyepiece of a compound microscope. The droplet is observed just after the pressure pulse is applied and disappears within a few seconds as the injected solution diffuses into the cytoplasm. We assume that the injected droplet is spherical. Electrophoretic injection of cAMP was quantified by measuring the charge delivered by the injection circuit, assuming a cAMP transport number of 0.05 (Connor and Hockberger, 1984). We estimated the cell volume by measuring the diameter of the cell and assuming a spherical geometry. The estimates of intracellular concentrations are expected to be somewhat low because glial cell proccsses may invaginate the neuronal cell body.

Much of the analysis involves changes in the kinetics of $I_{A}$ activation and inactivation. In quantifying changes in kinetics we used a nonlinear least-squares method implemented on a PDP 11/23 to find the best fit between specified theoretical curves and the measured data points (algorithm of Marquardt, 1963, as described by Bevington, 1969). Computed curves were displayed along with the data points on the computer terminal to allow the adequacy of the fitting procedure to be verified by inspection.

\section{Results}

Forskolin reduces the amplitude of the transient $\mathrm{K}$ current, $I_{A}$, and causes characteristic changes in the waveform of the current. These effects reverse after washing with normal saline. Figure $1, A-C$, shows transient $\mathrm{K}$ currents in normal saline, after applying forskolin to the bath, and after recovery. $I_{A}$ was activated by a depolarizing pulse to $-30 \mathrm{mV}$ from a conditioning voltage of $-90 \mathrm{mV}$. In the control, $I_{A}$ is an outward current that activates over a sigmoid time course, peaks in $30 \mathrm{msec}$, and then inactivates exponentially with a time constant of $200 \mathrm{msec}$. After $10 \mathrm{~min}$ in forskolin, the peak amplitude of $I_{A}$ is reduced to 0.55 times the control amplitude (range, $0.34-0.75 ; n=51$ ) and the waveform of the current is markedly changed, especially the apparent time course of inactivation. Inactivation in forskolin has an initial phase that is faster than normal and a final phase that is much slower than normal. This change in the waveform of the current was characteristic of forskolin's effect on $I_{A}$ in dorid neurons and is qualitatively different than the effect of 


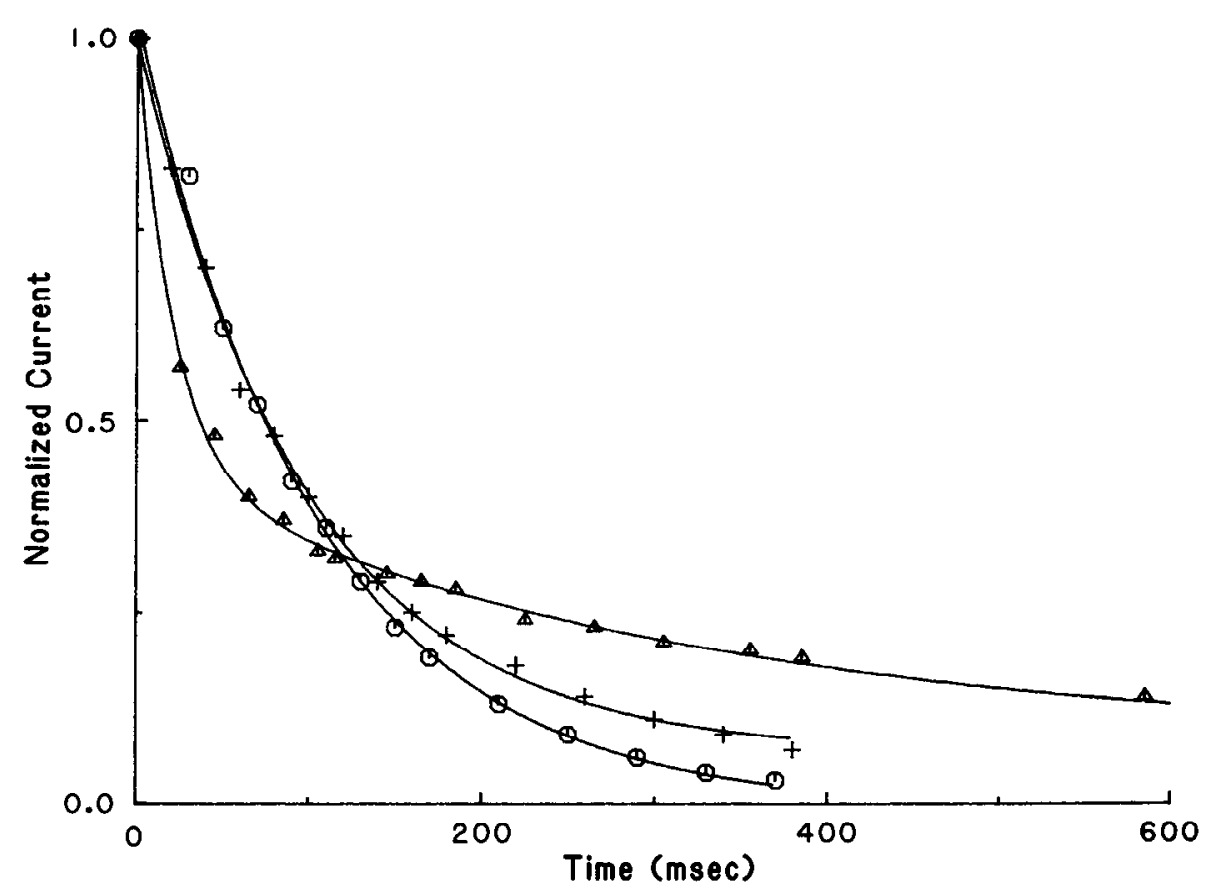

Figure 2. Time course of $I_{A}$ inactivation. $I_{A}$ was activated by a pulse to -30 from a conditioning voltage of -90 $\mathrm{mV}$. The current was measured at various times after the peak. The currents were normalized to the same peak amplitude. The circles show the inactivation of $I_{A}$ during the pulse in normal saline; the solid line through the points is an exponential with a time constant of $105 \mathrm{msec}$; the triangles show the time course of inactivation $68 \mathrm{~min}$ after adding $100 \mu \mathrm{M}$ forskolin to the bath; the solid line is the sum of 2 exponentials with time constants of 22 and $308 \mathrm{msec}$; the crosses show the time course of inactivation $10 \mathrm{~min}$ after washing with normal saline. The time course of inactivation in this case is reasonably well fit by a single exponential with time constant of 99 msec. Pedal ganglion cell from $D$. albopunctata. forskolin on $I_{A}$ in Aplysia bag cell neurons, where forskolin causes a decrease in the peak amplitude and a faster initial rate of inactivation but where the slow phase of inactivation is not observed (Strong, 1984).

The transient outward current in the control and in forskolin is completely blocked by $3 \mathrm{~mm}$ external DAP, a relatively specific blocker of $I_{A}$ in these cells (Thompson, 1977, 1982). The sensitivity to DAP suggests that both the rapidly inactivating current and the slowly inactivating current in forskolin are due to $I_{A}$ rather than a change in some other ionic current. The decrease in the amplitude of $I_{A}$ in forskolin does not result from a change in reversal potential. The reversal potential was determined by measuring tail currents at a number of hyperpolarized voltages after activating the current with a standard test pulse. The reversal potential $(-70 \mathrm{mV}$; range, -63 to $-77 \mathrm{mV}$; $n=7$ ) was the same in the control, at the peak of the current in forskolin, and at a isochrone $300 \mathrm{msec}$ after the beginning of the pulse that emphasizes the current during the slow inactivation caused by forskolin. These results are consistent with the idea that the modified transient current in forskolin is due specifically to a change in $I_{A}$ rather than a change in another current with a different reversal potential.

Forskolin also activated an inward current at the $-40 \mathrm{mV}$ holding voltage in 15 of the 19 experiments where recordings were made at high enough gain to detect small changes in holding current. The inward current began within 1 min after applying forskolin and reached an average amplitude of $3.1 \mathrm{nA}( \pm 1.54$ $\mathrm{nA}$ SD) within about $10 \mathrm{~min}$ (Fig. $1 D$ ). It was maintained throughout experiments lasting more than $1 \mathrm{hr}$ and recovered after washing with normal saline. This inward current resembles the cAMP-dependent inward current that is activated in this voltage range in molluscan neurons (Pellmar, 1981; Aldenhoff et al., 1983; Green and Gillette, 1983; Connor and Hockberger, 1984). In 4 experiments, however, forskolin did not activate the inward current, although it did cause the characteristic changes in $I_{A}$ amplitude and waveform (see also Connor and Hockberger, 1984). This suggests that the inward current and the changes in
$I_{A}$ may represent separate effects of forskolin that can occur independently. A water-soluble analog of forskolin (forskolin, 7-diacetyl-7-O-hemisuccinic acid) had no effect on the amplitude or waveform of $I_{A}$ and did not activatc inward current when applied at an external concentration of $100 \mu \mathrm{M}$ for periods up to $1 \mathrm{hr}(n=4)$.

\section{Effect on inactivation kinetics}

Forskolin modifies the kinetics of $I_{A}$ inactivation. In the example shown in Figure $2, I_{A}$ inactivates over an exponential time course with a time constant of $105 \mathrm{msec}$ in normal saline. After 68 min in forskolin the peak amplitude of $I_{A}$ is reduced to 0.54 times the control amplitude and the time course of inactivation is changed so that it is now best described by the sum of 2 exponentials with time constants of 22 and $308 \mathrm{msec}$. Twenty minutes after washing with normal saline the inactivation time course is again well fit by a single exponential with a time constant of $99 \mathrm{msec}$. Similar changes in inactivation kinetics were seen over a wide range of activation voltages and test pulse repetition rates. In every experiment forskolin caused an initial rate of inactivation that was faster than the control and a final rate that was much slower.

In some cells the time course of inactivation in forskolin could not be fit by the sum of 2 exponentials. In these cells the current during the test pulse decayed rapidly to a local minimum and then increased again to make a shallow hump of outward current that preceded the final slow decay as shown in Figure $1 B$. This waveform developed gradually, and although it was seen in most of the cells that were exposed to forskolin for more than $30 \mathrm{~min}$, it was seldom seen with shorter exposures.

The removal of $I_{A}$ inactivation during hyperpolarizing pulses was not strongly affected by forskolin. Removal of inactivation was measured by holding the cell at $-40 \mathrm{mV}$ and applying a series of increasingly longer conditioning hyperpolarizations. The peak amplitude of $I_{A}$ during a test pulse to $-30 \mathrm{mV}$ provided a measure of the level of inactivation obtained during the preceding hyperpolarization. The amplitude of $I_{A}$ during each 
Figure 3. Time course of removal of inactivation during a hyperpolarizing pulse. The cell was held at $-40 \mathrm{mV}$ and a series of increasingly longer pulses to $-90 \mathrm{mV}$ was applied. The peak amplitude of $I_{A}$ was measured on stepping to $-30 \mathrm{mV}$ after each conditioning pulse. The pulse paradigm is shown in the insert. Current amplitudes normalized to the amplitude after a $1 \mathrm{sec}$ pulse are plotted against conditioning pulse length. The open circles show currents during test pulses in normal saline; the crosses show currents recorded $30 \mathrm{~min}$ after applying $100 \mu \mathrm{M}$ forskolin; the stars show currents measured at an isochrone $200 \mathrm{msec}$ after the beginning of the pulse to $-30 \mathrm{mV}$ in forskolin. $D$. albopunctata pedal ganglion cell.

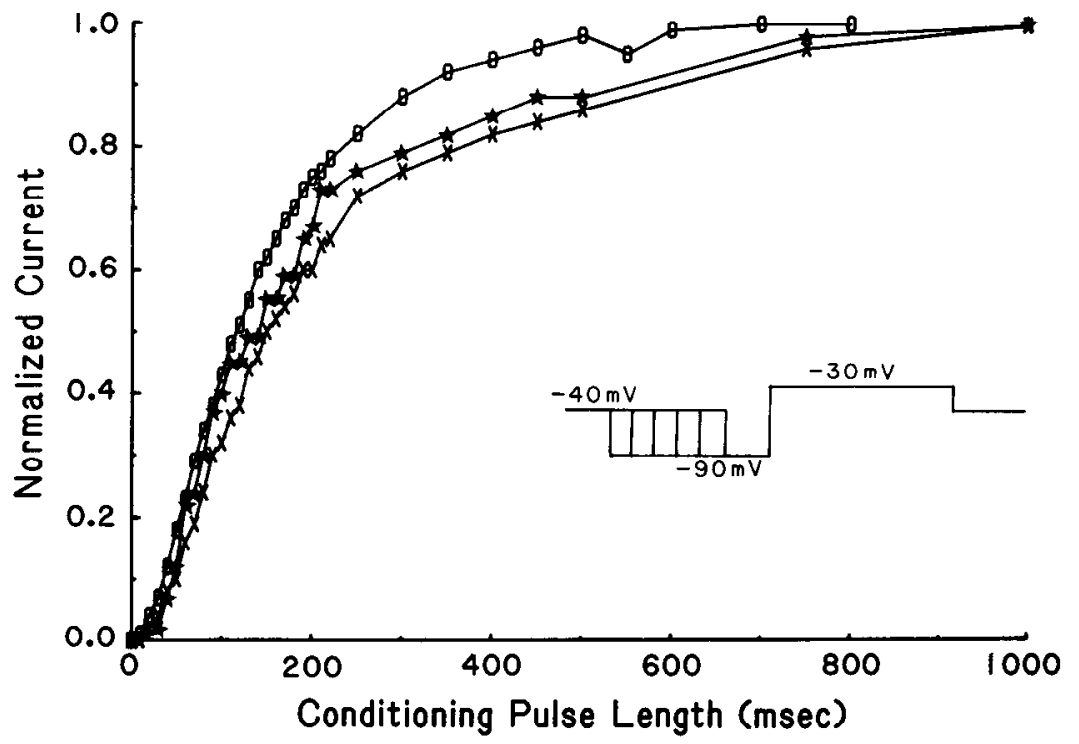

test pulse was normalized to the amplitude observed after a 1 sec conditioning hyperpolarization and plotted against conditioning pulse length to estimate the time course of removal of inactivation. In the example shown in Figure 3, the removal of inactivation at $-90 \mathrm{mV}$ in normal saline follows an exponential time course with a time constant of $154 \mathrm{msec}$. After $36 \mathrm{~min}$ in forskolin the removal of inactivation is still best fit by a single exponential with a time constant of $192 \mathrm{msec}$. Figure 3 also shows the removal of inactivation measured from the amplitude of the current at an isochrone $200 \mathrm{msec}$ after the beginning of the test pulse. This measurement emphasizes the slowly inactivating current that develops in forskolin. The results show that the removal of inactivation has nearly the same time course whether $I_{A}$ is measured at the peak of the current or at the 200 msec isochrone and support the conclusion that the transient current in forskolin is due specifically to $I_{A}$. Similar results were obtained using a number of conditioning voltages in 7 experiments. The results in dorid neurons differ from those obtained in Aplysia bag cell neurons, where forskolin causes a faster initial rate of removal of $I_{A}$ inactivation during hyperpolarizing pulses (Strong, 1984).

\section{Effect on activation kinetics}

Forskolin modifies the rate of $I_{A}$ activation during depolarizing pulses. Early in the pulse the current activates at nearly the normal rate, but a slower rate becomes apparent later in the pulse. Figure $4 A$ shows the rising phase of $I_{A}$ on stepping to -30 $\mathrm{mV}$ from a holding voltage of $-80 \mathrm{mV}$ in the control and after $48 \mathrm{~min}$ in forskolin. Figure $4 B$ shows the 2 currents scaled to the same peak amplitude. The scaled currents follow approximately the same time course at the beginning of the depolarization, but the current in forskolin peaks earlier. Following the usual interpretation of $I_{A}$ gating, which views activation and inactivation as independent, the waveform of the current in forskolin is consistent with the idea that the current early in the test pulse activates at approximately the normal rate but inactivates more quickly.

Another component of the transient $\mathrm{K}$ current activates more slowly than normal after exposure to forskolin. This was shown by measuring tail currents during pulses to $-90 \mathrm{mV}$ after a test pulse to $-30 \mathrm{mV}$. The tail current at $-90 \mathrm{mV}$ is inward and results from the closing of $I_{A}$ channels activated by the test pulse. By varying the duration of the test pulse and measuring the amplitudes of tail currents, one can determine the time course of the conductance change underlying $I_{A}$. In the control the tail current decays quickly (Fig. $5 A$ ). The tail current measurements were repeated after the cell was exposed to forskolin for $20 \mathrm{~min}$ (Fig. 5B). After short activating pulses, shorter than the normal time to peak, the tail current decays at about the same rate as the control. With longer test pulses, however, a slow component of the tail current begins to appear, and late in the pulse during the slow inactivation caused by forskolin, only slow tail current is seen. The simplest interpretation of these results is that in forskolin the transient $\mathrm{K}$ current is composed of 2 components. One component activates at approximately the normal rate but inactivates more quickly than normal, while the other activates and inactivates more slowly. This interpretation readily accounts for transient currents like that shown in Figure 1B; currents that reach a peak, inactivate quickly to a minimum, and then increase again before inactivating slowly. The alternative explanation, that all of the current activates at nearly the normal rate but part inactivates quickly and part inactivates slowly, is not supported by the data in Figure 5 .

\section{Voltage dependence of activation and inactivation}

Forskolin does not change the voltage dependence of $I_{A}$ activation or inactivation. Strong (1984) reached the same conclusion after studying the effects of forskolin on $I_{A}$ in Aplysia bag cell neurons. The steady-state voltage dependence of activation was measured by applying a conditioning pulse to $-90 \mathrm{mV}$ for $1 \mathrm{sec}$ and then stepping to a series of more depolarized test voltages. The peak amplitude of the current during each test pulse was used to estimate the relative activation of $I_{A}$. Peak amplitudes were plotted against the test pulse voltage to construct an activation-voltage curve. This procedure can only be applied at test voltages below about $-20 \mathrm{mV}$ because at more depolarized voltages inward $\mathrm{Na}$ and $\mathrm{Ca}$ currents and other $\mathrm{K}$ currents begin to activate. The voltage dependence of activation in the control, $22 \mathrm{~min}$ after adding forskolin, and $10 \mathrm{~min}$ after washing with normal saline, is shown in Figure 6 . Although the amplitude of $I_{A}$ is reduced by forskolin, the activation-voltage curves scale reasonably linearly over the voltage range where 
A

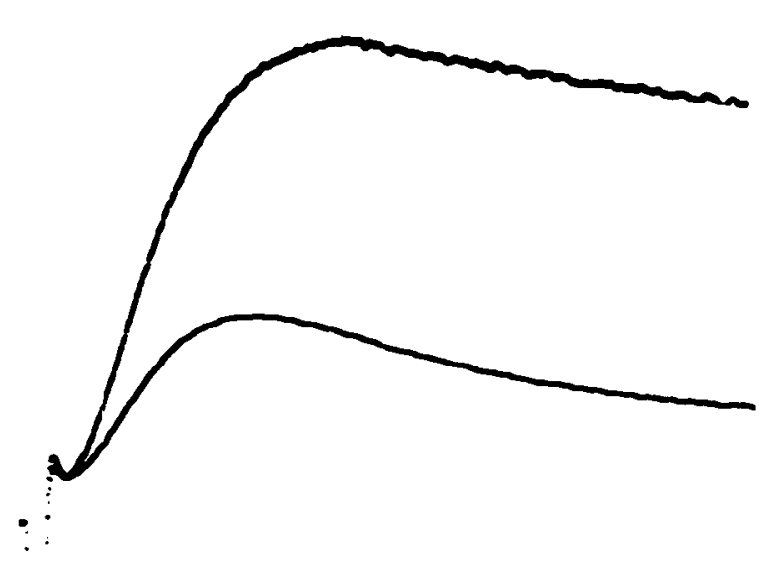

B

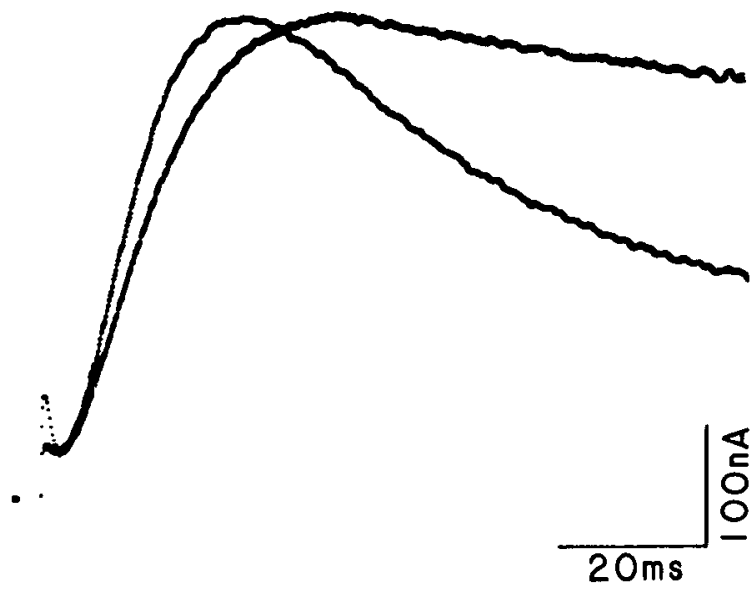

Figure 4. $A, I_{A}$ during a pulse to $-30 \mathrm{mV}$ from a conditioning voltage of $-90 \mathrm{mV}$ in normal saline (larger trace) and $48 \mathrm{~min}$ after adding 100 $\mu \mathrm{M}$ forskolin. $B$, The currents scaled to the same peak amplitude. The current in forskolin has a faster initial rate of inactivation. Pedal ganglion cell from D. albopunctata.

uncontaminated measurements can be made. Figure 6 also shows the activation-voltage curve for current measured $300 \mathrm{msec}$ after the beginning of the test pulse. The current at this time emphasizes the slowly activating part of $I_{A}$ in forskolin and it is seen that this component of the current has about the same voltage dependence as the component that activates more rapidly.

To measure the steady-state voltage dependence of inactivation the cell was voltage-clamped to a series of conditioning voltages between -50 and $-100 \mathrm{mV}$ for $1 \mathrm{sec}$ prior to a test pulse to $-30 \mathrm{mV}$. The amplitude of $I_{A}$ during the test pulse was measured at its peak and at an isochrone $300 \mathrm{msec}$ after the beginning of the pulse. These measurements provide an estimate of the steady-state level of inactivation during the preceding hyperpolarization. The voltage dependence of inactivation is plotted in Figure $7 \mathrm{~A}$ for a cell in normal saline, $22 \mathrm{~min}$ after applying forskolin, and 10 min after returning to normal saline. Figure $7 B$ shows the same curves normalized to the amplitude after a conditioning pulse to $-100 \mathrm{mV}$. The amplitude of the current is decreased in forskolin, but the voltage dependence of inactivation is about the same as the control. Figure $7 B$ also shows that in forskolin the steady-state voltage dependence of inactivation is the same whether the current is measured at its
A

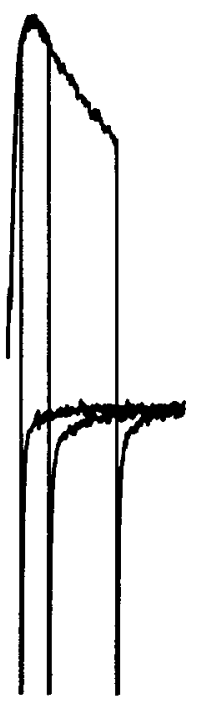

B

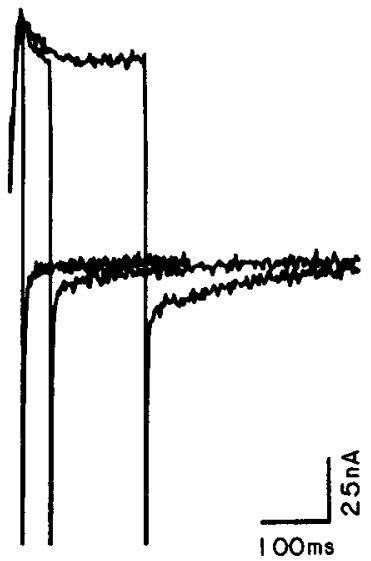

Figure 5. $I_{A}$ tail currents in control saline and in forskolin. $I_{A}$ was activated by pulses to $-30 \mathrm{mV}$ from $-90 \mathrm{mV}$. Tail currents were recorded on stepping to $-90 \mathrm{mV}$ at various times during the transient outward current. $A$, Tail currents measured 20,60 , and $160 \mathrm{msec}$ after the pulse to $-30 \mathrm{mV}$ in normal saline. $B$, Tail currents after bathing the cell in $100 \mu \mathrm{M}$ forskolin for $20 \mathrm{~min}$. Tail currents were measured 20,60 , and $200 \mathrm{msec}$ after the pulse to $-30 \mathrm{mV}$. A. nobilis pedal ganglion cell.

peak or at the $300 \mathrm{msec}$ isochrone. The experiments on the voltage dependence of activation and inactivation support the conclusion that both the rapidly activating current and the slowly activating current in forskolin are due to $I_{A}$.

\section{Time course of forskolin action}

The effects of forskolin on $I_{A}$ develop slowly (see also Strong, 1984). In the example shown in Figure 8, the amplitude and waveform of $I_{A}$ remain about the same for nearly $30 \mathrm{~min}$ after

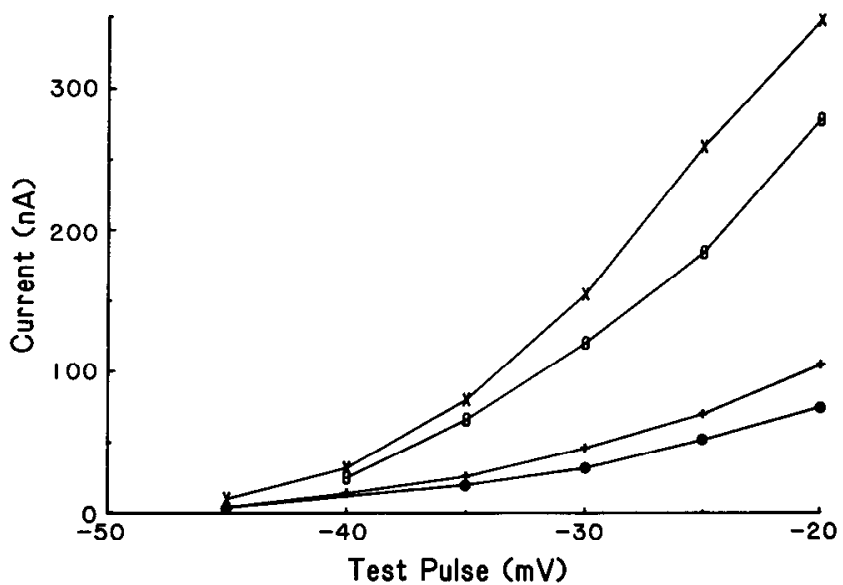

Figure 6. Steady-state voltage dependence of $I_{A}$ activation. $I_{A}$ was measured during a series of $1 \mathrm{sec}$ test pulses from a conditioning voltage of $-90 \mathrm{mV}$. Peak current amplitudes are plotted against test voltage in control saline (open circles), after $22 \mathrm{~min}$ in $100 \mu \mathrm{M}$ forskolin (plusses), and $20 \mathrm{~min}$ after washing away forskolin with control saline (crosses). The filled circles show the amplitude of the current in forskolin at an isochrone $300 \mathrm{msec}$ after the beginning of the test pulse. A. nobilis pedal cell. Same cell as in Figure 7. 

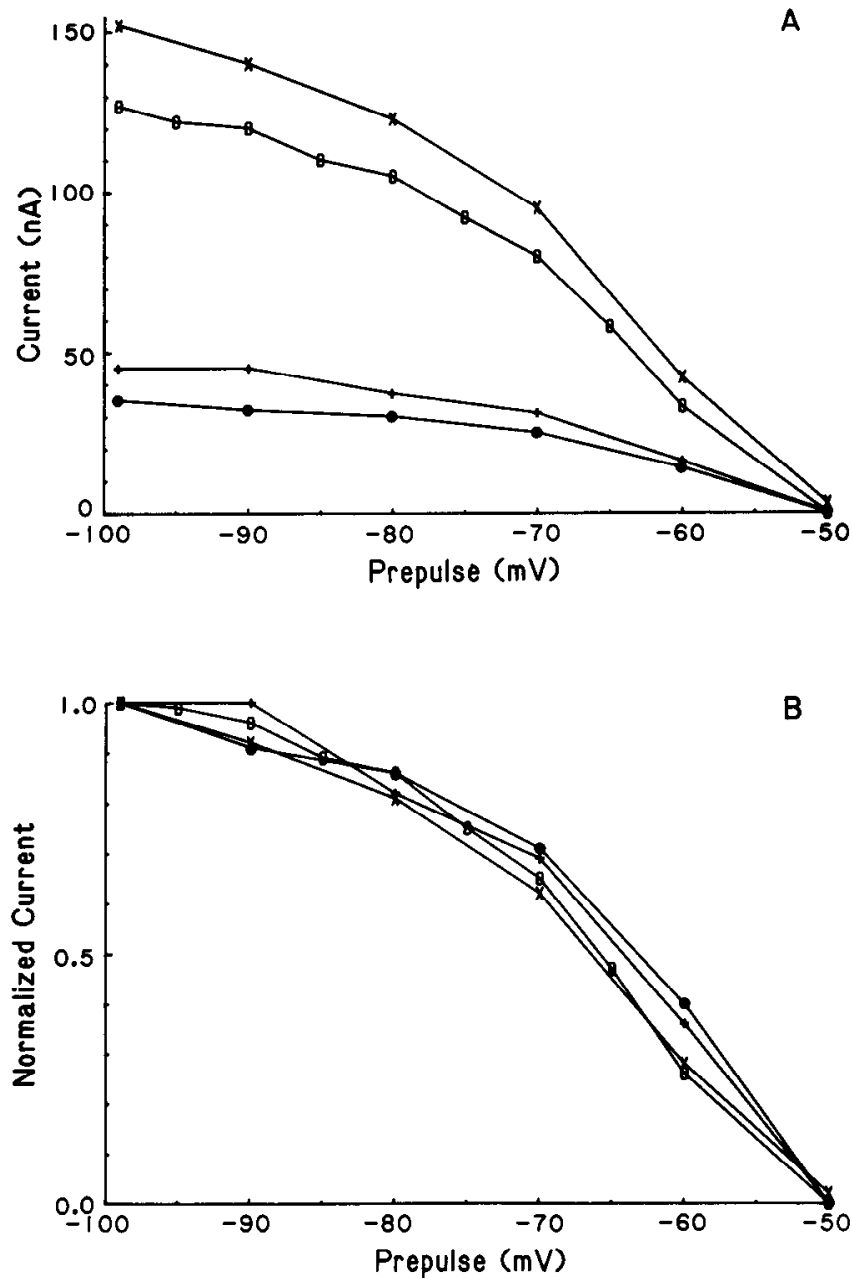

Figure 7. Steady-state voltage dependence of inactivation. $I_{A}$ was activated by a pulse to $-30 \mathrm{mV}$ from a series of $1 \mathrm{sec}$ conditioning pulses to different voltages. $A$, The amplitudes of transient outward currents during the pulses to $-30 \mathrm{mV}$ are plotted against the conditioning voltage. The open circles show the peak amplitudes of $I_{A}$ in normal saline; the plusses show currents $22 \mathrm{~min}$ after adding $100 \mu \mathrm{M}$ to the bath; the crosses are the currents $10 \mathrm{~min}$ after washing with control saline. The amplitudes of currents at an isochrone $300 \mathrm{msec}$ after the beginning of the test pulses are also plotted (filled circles). $B$, Same curves normalized to the current after a conditioning pulse to $-100 \mathrm{mV}$. All of the data are from the same $A$. nobilis pedal cell.

applying forskolin to the bath and then change gradually over the next $30 \mathrm{~min}$. In different cells the first indication of a decrease in $I_{A}$ amplitude and change in current waveform occurred 5-60 min after adding forskolin. The rate at which the effects developed was not influenced in a consistent way by adding phosphodiesterase inhibitors (1 mM IBMX or $80 \mu \mathrm{M}$ RO20 1724). Instead, the variability in time course appeared to be related to the way forskolin was introduced into the bath and the bath tempcraturc. Forskolin is not water soluble, which makes it difficult to deliver to the cells. When a concentrated stock solution of forskolin in $\mathrm{EtOH}$ was added to the bath with adequate stirring, the effects on $I_{A}$ developed relatively quickly, within 5$10 \mathrm{~min}$, at the warmest temperatures used in this study $\left(17^{\circ} \mathrm{C}\right)$. When the bath was not well stirred or when experiments were conducted at cooler temperatures, the changes in $I_{A}$ developed more slowly. At $10^{\circ} \mathrm{C}$, forskolin precipitated upon adding the $\mathrm{EtOH}$ stock solution. Stock solutions prepared in DMSO were

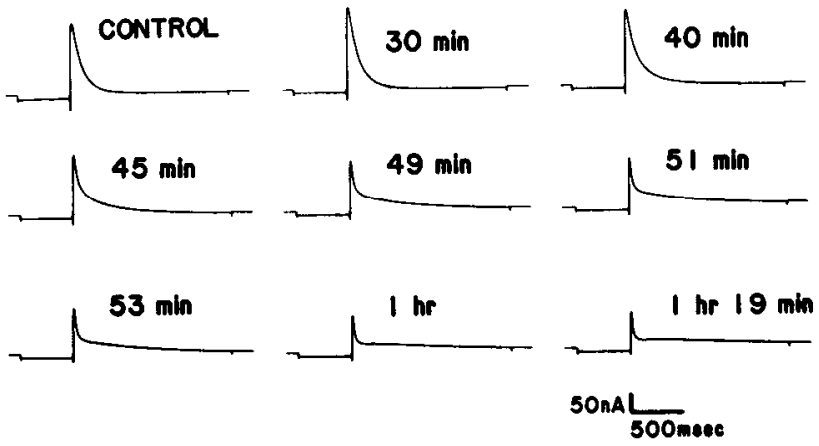

Figure 8. Development of forskolin's effect. The cell was held at -40 $\mathrm{mV}$, and a $500 \mathrm{msec}$ conditioning pulse to $-90 \mathrm{mV}$ was applied before activating $I_{A}$ with a pulse to $-30 \mathrm{mV}$. Transient outward currents were recorded in control saline and at various times after adding $100 \mu \mathrm{M}$ forskolin to the bath. Pedal ganglion cell from $D$. albopunctata.

more difficult to work with because DMSO gelled at temperatures below about $17^{\circ} \mathrm{C}$. The slow rate of development of forskolin's effects on $I_{A}$ probably reflects its low solubility in water at the temperatures used in this study. However, we always found that forskolin's effect on $I_{A}$ developed more slowly than the inward current observed at the holding voltage. The inward current began with a delay of less than $1 \mathrm{~min}$ and reached a maximum amplitude within 10 min even in experiments where the first sign of a change in $I_{A}$ did not appear for $30 \mathrm{~min}$. We return to this point in the Discussion.

\section{Effects of CAMP}

If the modification of $I_{A}$ by forskolin required cAMP, one would expect procedures that increase the intracellular concentration of cAMP to produce similar effects. Cyclic AMP was injected into cells in 8 experiments to achieve an estimated cytoplasmic concentration of $1 \mu \mathrm{M}-16 \mathrm{mM}$, and it was found that the amplitude and waveform of $I_{A}$ were not altered. Cyclic AMP activated an inward current at the $-40 \mathrm{mV}$ holding voltage that is probably the same as the cAMP-dependent inward current described by Pellmar (1981), Aldenhoff et al. (1983), Green and Gillette (1983), and Connor and Hockberger (1984). The inward current began within $1 \mathrm{~min}$ after the injection, reached a peak within $4 \mathrm{~min}$, and recovered within 6-9 min. It approached a saturating amplitude of 2-10 nA. Figure $9 C$ shows the inward current resulting from electrophoretic injection of cAMP (estimated cytoplasmic concentration, $0.9 \mathrm{~mm}$ ). Unlike the inward current activated by forskolin, the current activated by cAMP injection is transient, probably because the injected cAMP is hydrolyzed in the cell. The duration of the current was slightly prolonged by applying the phosphodiesterase inhibitor IBMX (1-2 mM), but it still recovered 12-20 min after injection.

It was important to determine if the characteristic changes in $I_{A}$ that are caused by forskolin could be reproduced by a prolonged increase in intracellular cAMP concentration. In 3 experiments cells were bathed in an external solution containing $1 \mathrm{mM}$ IBMX and multiple electrophoretic injections of cAMP were performed in order to maintain a high intracellular concentration for periods up to $1 \mathrm{hr}$. The cAMP-dependent inward current was monitored and injections were repeated at approximately $5 \mathrm{~min}$ intervals to keep the inward current near its saturated amplitude. Figure $9, A$ and $B$, shows $I_{A}$ measured with a standard test protocol before and $30 \mathrm{~min}$ after beginning repeated injections of cAMP. Figure $9 D$ plots the time course of 


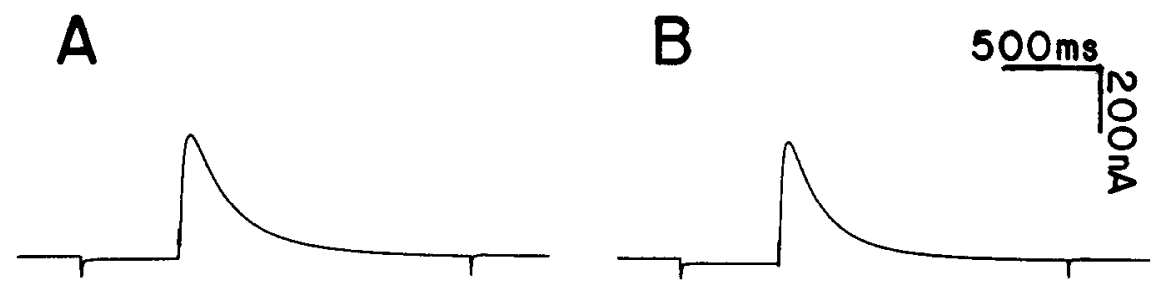

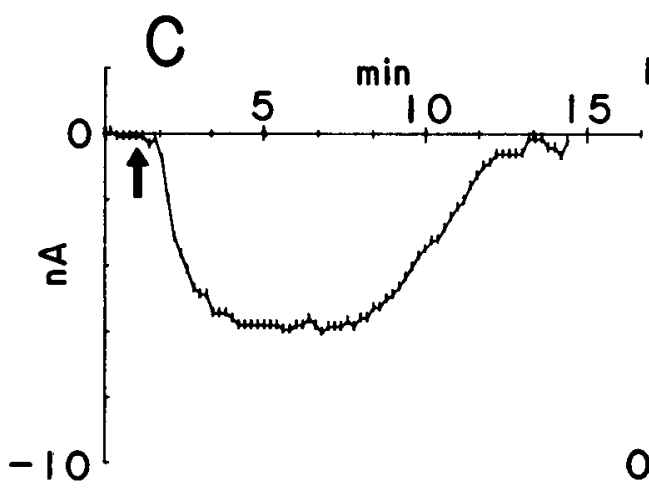

$I_{A}$ inactivation. Inactivation follows approximately the same time course in both records (control $\tau=236 \mathrm{msec}$; $30 \mathrm{~min} \tau=$ $206 \mathrm{msec}$ ). Therefore, even a prolonged increase in the intracellular concentration of cAMP did not change the amplitude or waveform of $I_{A}$.

Phosphodiesterase inhibitors can raise the intracellular concentration of CAMP by slowing or preventing its hydrolysis. In 8 experiments cells were treated with the phosphodiesterase inhibitors IBMX (1-2 mM) or RO20 $1724(80 \mu \mathrm{m})$, and it was found that they had no effect on the amplitude or waveform of $I_{A}$. Figure $10, A$ and $B$, shows $I_{A}$ activated by a standard test pulse before and $22 \mathrm{~min}$ after adding $1 \mathrm{mM}$ IBMX to the bath; Figure $10 D$ shows the time course of $I_{A}$ inactivation for the same 2 currents. In both control and IBMX salines the transient $\mathrm{K}$ current inactivates exponentially with the same time constant
Figure 9. Repeated electrophoretic injections of cAMP. $A$, Control current activated by a pulse to $-30 \mathrm{mV}$ following a $1 \mathrm{sec}$ conditioning hyperpolarization to $-90 \mathrm{mV} . B, I_{A}$ activated by the same pulse $30 \mathrm{~min}$ after beginning multiple injections of cAMP. (The cumulative injections would have brought the cAMP concentration to $15 \mathrm{mM}$ if no hydrolysis or inactivation of the injected cAMP had occurred.) $C$. The inward current recorded at $-40 \mathrm{mV}$ following a single injection of cAMP (estimated cytoplasmic concentration, $0.9 \mathrm{~mm}$ ). $D$, The time course of inactivation of transient outward current in the control (solid line) and $30 \mathrm{~min}$ aftcr beginning the multiple injections of cAMP (dashed line). A. nobilis pedal ganglion neuron.

\section{sec}

(219 msec). In 3 experiments, cells were bathed in salines containing 1-2 mM IBMX or $80 \mu \mathrm{M}$ RO20 1724 for periods up to $4 \mathrm{hr}$; even after long incubations there was no change in the waveform of $I_{A}$. After treating the cells with phosphodiesterase inhibitors, forskolin was added to the bath, and it always caused the characteristic decrease in amplitude and change in $I_{A}$ waveform. IBMX also causes the activation of inward current at the $-40 \mathrm{mV}$ holding potential, an effect reported previously by Connor and Hockberger (1984). The inward current began less than 1 min after applying IBMX and reached a maximum amplitude of about $8 \mathrm{nA}$ within $20 \mathrm{~min}$ (Fig. 10C). The inward current was maintained for the duration of the experiment (1 hr) and recovered on washing with normal saline.

Membrane-permeable analogs of cAMP did not reproduce the effects of forskolin on $I_{A}$. A total of 16 experiments was
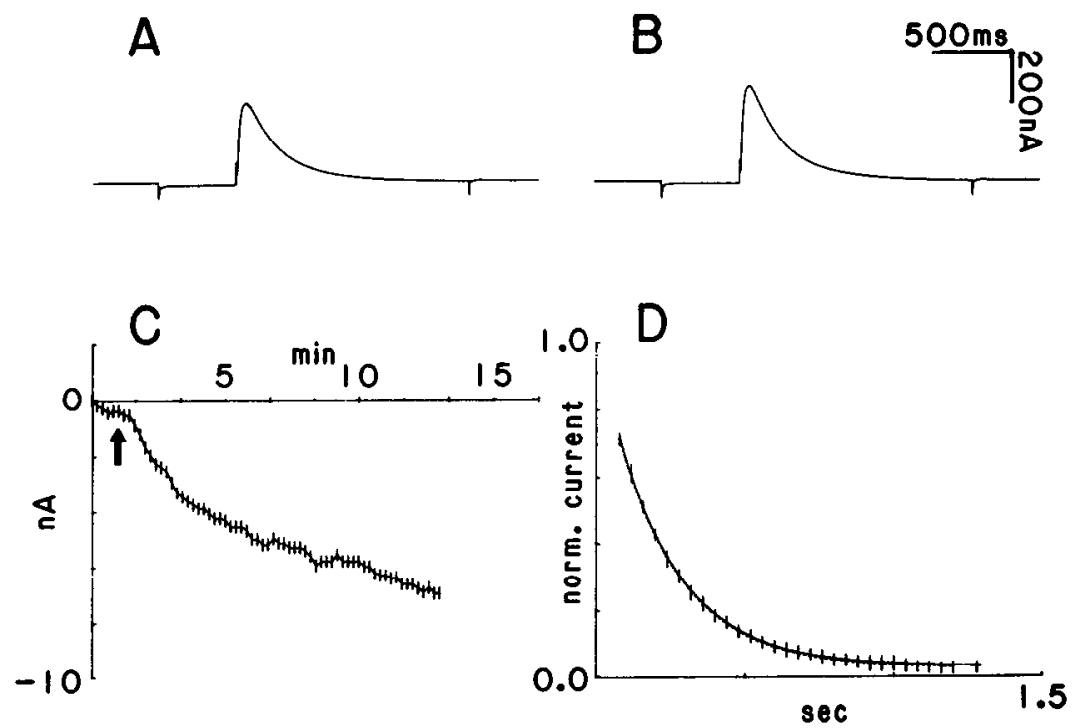

Figure 10. Effect of IBMX. A, Control current activated by a pulse to $-30 \mathrm{mV}$ following a $500 \mathrm{msec}$ conditioning hyperpolarization to $-90 \mathrm{mV} . B, I_{A}$ activated by the same pulse $22 \mathrm{~min}$ after adding $1 \mathrm{mM}$ IBMX to the bath. $C$, Time course of inward current activated by IBMX at $-40 \mathrm{mV}$. $D$, Time course of $I_{A}$ inactivation in the control and 22 min after adding IBMX. The solid lines are exponentials fitted to the data points. $A$. nobilis pedal ganglion neuron. 
A

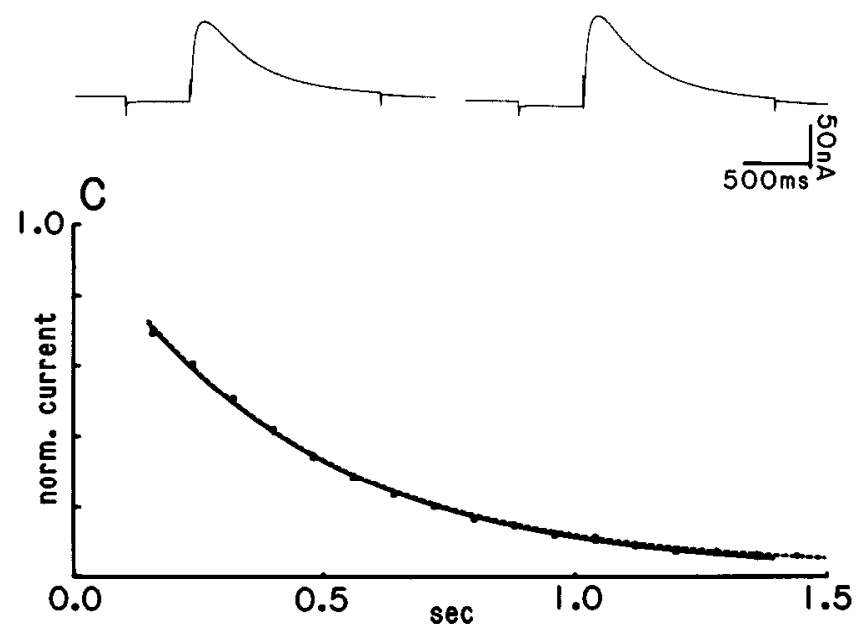

Figure 11. Effect of 8-bromo-cAMP on $I_{A}$ and on holding current. $A$, Control current activated by a pulse to $-30 \mathrm{mV}$ after a $500 \mathrm{msec}$ conditioning pulse to $-90 \mathrm{mV} . B, I_{A}$ activated by the same pulse 30 min after adding $1 \mathrm{~mm} 8$-bromo-cAMP to the bath. $C$, The time course of $I_{A}$ inactivation in the control and in 8-bromo-cAMP. The solid lines are exponentials fitted to the data points. $A$. nobilis pedal ganglion neuron.

performed using clorophenylthio-cAMP (1.2 mM, $n=7)$, 8-bromo-cAMP (1-1.2 mM, $n=5)$, and dibutyrl-cAMP (1 mM, $n=4)$. Figure $11, A$ and $B$, shows $I_{A}$ in the control saline and $30 \mathrm{~min}$ after adding 8-bromo-cAMP; The time course of inactivation of the 2 currents is shown in Figure $11 \mathrm{C}$. The cAMP analog had little effect on the amplitude or time course of $I_{A}$. Similar results were obtained with all of the cAMP analogs. In 3 experiments cells were preincubated with cAMP analogs for 3-5 hr before voltage clamping. Even after long incubations $I_{A}$ appeared to have the normal waveform. Following the treatment with cAMP analogs, forskolin added to the bath always caused a decrease in the amplitude and the characteristic change in the waveform of $I_{A}$. Eight experiments were performed to determine if the CAMP analogs activate an inward current at the $-40 \mathrm{mV}$ holding potential, as previously reported by Connor and Hockberger (1984) and Aldenhoff et al. (1983). Inward current was activated in every case. It began within $10 \mathrm{sec}$ after adding the cAMP analog, reached a steady amplitude of 2-10 nA within $20 \mathrm{~min}$, and was maintained throughout experiments lasting up to $1 \mathrm{hr}$. The holding current recovered after washing with normal saline. From these experiments we conclude that cAMP injection, cAMP analogs, and phosphodiesterase inhibitors can all activate inward current at the holding voltage, but they do not modify the amplitude or time course of $I_{A}$.

\section{Injection of protein kinase and kinase inhibitor}

The active catalytic subunit of cAMP-dependent protein kinase was pressure-injected into neurons in 6 experiments to achieve an estimated intracellular concentration of $0.4-19.0 \mu \mathrm{g} / \mathrm{ml}$. Three experiments used a protein kinase preparation provided by Dr. Irwin Levitan, while the others used Sigma protein kinase. $I_{A}$ was activated with a standard protocol before and up to $1 \mathrm{hr}$ after kinase injection, and it was found that protcin kinasc did not affect the amplitude or waveform of $I_{A}$. In 1 cell, protein kinase appeared to activate an inward current at the $-40 \mathrm{mV}$ holding potential. The inward current began about $400 \mathrm{msec}$ after the injection, reached a peak amplitude of $12.5 \mathrm{nA}$ in 1.5 sec, and recovered within $5 \mathrm{sec}$. The inward current resulted from a transient conductance increase but was not studied in detail. In 1 other experiment, protein kinase appeared to cause a maintained increase in inward rectifier current.

The heat-stable inhibitor of cAMP-dependent protein kinase was pressure-injected into 6 neurons in an attempt to dissociate the effects of forskolin on $I_{A}$ from the activation of endogenous cAMP-dependent protein kinase (see Adams and Levitan, 1982). Protein kinase inhibitor did not prevent or reverse the effect of forskolin on $I_{A}$. Two kinds of experiments were performed. In the first $(n=2)$, the inhibitor was injected (estimated cytoplasmic concentration, $0.04-0.21 \mu \mathrm{g} / \mathrm{ml}$ ) before applying forskolin to the bath. The inhibitor did not prevent the decrease in $I_{A}$ amplitude or the change in current waveform that characteristically resulted from forskolin. This is not an entirely satisfactory experiment, however, because the inhibitor may be inactivated in the cytoplasm before forskolin has time to produce its effect. In the second kind of experiment $(n=4)$, the protein kinase inhibitor was injected after applying forskolin. $I_{A}$ was measured with a standard test pulse before and after adding forskolin to the bath. Protein kinase inhibitor was pressure-injected into the cell when a change in the waveform of $I_{A}$ first became apparent. The injection of inhibitor did not reverse the effects of forskolin on $I_{A}$ even temporarily.

\section{Discussion}

Forskolin changes the apparent kinetics of $I_{A}$ activation and inactivation in a complicated way. It was important to determine if all of the effects of forskolin resulted from a modification of $I_{A}$ or whether the drug modified a different outward current, causing it to activate and inactivate slowly at voltages like those used to study $I_{A}$, a question that has been raised appropriately by Strong (1983). Our results indicate that the changes in ionic current observed in the voltage range we studied involve $I_{A}$ specifically. The observations supporting this conclusion are as follows: (1) In forskolin, the voltage dependence of $I_{A}$ activation and inactivation is the same for currents measured at the peak of the transient and for currents measured 200-300 msec after the peak, a time that emphasizes the slowly activating component of the current. (2) The time course of removal of inactivation during hyperpolarizing pulses is the same whether test currents are measured at the peak of the current or at an isochrone 200-300 msec after the beginning of the test pulse. (3) The reversal potential for transient current in forskolin is the same at the peak of the current and at the 200-300 msec isochrone. And (4) both the rapidly activating current and the slowly activating current are blocked by DAP, a relatively specific blocker of $I_{A}$ in these cells (Thompson, 1977, 1982).

Forskolin activates adenylate cyclase in a variety of cells, and for this reason it is an important pharmacological tool for studying the effects of cAMP on neuronal excitability. Kauer and Kaczmarek (1985) showed that forskolin causes a 3- to 4-fold increase in intracellular cAMP concentration in Aplysia bag cell neurons using radioimmunoassay. Deterre et al. (1982) reported a 9-fold increase in cAMP concentration after applying forskolin to certain Helix neurons. The fact that forskolin can activate an inward current that rescmbles the cAMP-dependent inward current in dorid neurons is a strong indication that forskolin activates adenylate cyclase in these cells as well. Our experiments show, however, that forskolin's effect on $I_{A}$ is not related to the 
stimulation of adenylate cyclase. External application of phosphodiesterase inhibitors and membrane-permeable analogs of cAMP and intracellular injection of cAMP did not reproduce the effects of forskolin on $I_{A}$. The decrease in $I_{A}$ amplitude and the characteristic change in current waveform in forskolin were not prevented or reversed by intracellular injection of an inhibitor of cAMP-dependent protein kinase. Furthermore, intracellular injection of the active catalytic subunit of cAMP-dependent protein kinase did not reproduce the effect of forskolin on $I_{A}$ in dorid cells, although Alkon et al. (1983) did find that protein kinase injection caused a small reduction in $I_{A}$ amplitude in Hermissenda photoreceptors.

The inward current activated by cAMP resembles the current studied in detail by Connor and Hockberger (1984) in these cells and by Pellmar (1981), Green and Gillette (1983), and Aldenhoff et al. (1983) in other molluscan neurons. The current was transient, suggesting that the cell possesses a pool of phosphodiesterase capable of hydrolyzing the injected cAMP within minutes. The cAMP-dependent inward current was not greatly prolonged by IBMX or RO20-1724, indicating that the cellular phosphodiesterase was not completely inhibited. In most cells, forskolin also activated an inward current (see Walsh and Byrne, 1985). Unlike the current activated by cAMP injection, the forskolindependent inward current was maintained for long periods. This is expected if forskolin forms a stable complex with adenylate cyclase in the membrane and causes the constitutive production of cAMP. In some experiments, however, forskolin failed to activate the inward current but still caused the characteristic changes in $I_{A}$. The conclusion we draw from these observations is that the effects of forskolin on $I_{A}$ can be separated from the stimulation of adenylate cyclase. Forskolin affects $I_{A}$ in ways that cAMP does not. Moreover, forskolin modifies $I_{A}$ in experiments in which it does not activate the cAMP-dependent inward current.

In Aplysia bag cell neurons, forskolin and membrane-permeable analogs of cAMP appear to produce similar changes in $I_{A}$ (Kaczmarek and Strumwasser, 1984; Strong, 1984), suggesting that the changes in $I_{A}$ that result from forskolin in bag cell neurons may require cAMP as an intermediate, while those in dorid neurons do not. Strong (1984) concluded that after applying forskolin to Aplysia bag cells, $I_{A}$ channels could be divided into 2 populations: a population with normal inactivation kinetics thought to represent channels that were unaffected by forskolin and a population with faster than normal inactivation that was thought to represent forskolin affected channels. The complicated changes in $I_{A}$ activation and inactivation kinetics that we observed in dorid neurons are not easily explained in this way, and they make a division of the channels into those affected by the drug and those not affected very difficult. The major difference between our findings and those of Strong is that in the dorid neurons we always observed a slowly activating and inactivating component of $I_{A}$. This slow component contributes $25-45 \%$ of the total current, whereas Strong saw either no slow current or only a minor slow component. It appears that Aplysia bag cell neurons respond differently to forskolin than do dorid neurons. A possible explanation for this is suggested by the observation that some cells possess more than 1 type of transient outward current (Sicgclbaum and Tsien, 1980; Coraboeuf and Carmeliet, 1982; MacDermott and Weight, 1982; Salkoff, 1983). Perhaps the Aplysia bag cells have only 1 type of transient current, whose inactivation becomes faster in for- skolin. The dorid cells may have two transient currents that have similar kinetics in the control saline but very different kinetics in forskolin. Forskolin could incrcase the rate of inactivation of 1 type and decrease the rates of activation and inactivation of the other. It is also possible that the differing results are due to methodological differences; Strong used an internal perfusion voltage-clamp method, whereas we used a 2-microelectrode voltage clamp applied to unperfused cells.

The changes in $I_{A}$ that result from forskolin develop more slowly than the increase in cytoplasmic cAMP concentration. Kauer and Kaczmarek (1985) measured a 2- to 4-fold increase in cAMP concentration within $5 \mathrm{~min}$ after applying forskolin to Aplysia bag cell neurons. In dorid neurons, the cAMP-dependent inward current begins in less than $1 \mathrm{~min}$ after applying IBMX or membrane-permeable analogs of cAMP and after intracellular injection of cAMP (see also Pellmar, 1981; Aldenhoff et al., 1983; Green and Gillette, 1983; Connor and Hockberger, 1984; Walsh and Byrne, 1985). Forskolin also causes rapid activation of inward current, but the changes in $I_{A}$ develop much more slowly. One possible explanation for the delay in the effect on $I_{A}$ is that cAMP might initiate a long sequence of cytoplasmic events that result in the production of an intermediate that modifies $I_{A}$ channels. The completion of the sequence might require prolonged elevation of the cytoplasmic cAMP concentration. We tested for this possibility by incubating cells for long periods in IBMX and cAMP analogs and by repeated cAMP injections that produced a maintained inward current, but we found no evidence for a delayed effect of cAMP on $I_{A}$. An alternative explanation for the delayed effect of forskolin on $I_{A}$ derives from the fact that forskolin, a lipid-soluble molecule, probably exerts its effects after entering the membrane (Seamon et al. 1984). Forskolin is minimally soluble in saline at the temperatures used in this study, and it probably enters the membrane slowly. When forskolin interacts with adenylate cyclase it engages a catalytic mechanism. Only a few adenylate cyclase enzyme complexes need be activated to amplify the signal and produce a large change in the cytoplasmic cAMP concentration. However, if forskolin were to act directly on individual $I_{A}$ channels to modify their activation and inactivation kinetics, a delay might be introduced because forskolin molecules would have to interact with a significant number of $I_{A}$ channels before the change could be detected.

The major effect of forskolin on $I_{A}$ in dorid neurons is a complicated change in the kinetics of activation and inactivation that resembles the effect of the $\mathrm{K}$ channel blockers 4-aminopyridine and DAP on this current (Thompson, 1982). One possible model for a direct pharmacological effect of forskolin is that it blocks the current in a manner similar to the aminopyridines. We looked for evidence of a voltage-dependent or usedependent block by forskolin without success, but because forskolin is so lipid soluble, voltage-dependent effects might be too rapid for us to resolve (see Hille, 1977). Support for blocking or local anesthetic-like action comes from recent studies on the effects of forskolin on nicotinic ACH receptors in PC12 cells. Forskolin was found to have an inhibitory, local anesthetic-like effect on carbachol-stimulated ${ }^{86} \mathrm{Rb}$ uptake, which was not mediated by cAMP (McHugh and Mcgee, 1986).

It is important to learn all of the roles that cAMP can play as a second messenger in the modulation of neuronal excitability, and because forskolin can directly activate adenylate cyclase, it can be useful in studying the effects of cAMP in intact 
cells. However, the results reported here show that forskolin may not act specifically on adenylate cyclase but may also have direct effects on $\mathbf{K}$ currents. If forskolin is to be used appropriately in studying the modulation of excitability by cAMP, the specificity of its action should be verified. The best approach at present requires comparison of the effects of forskolin with the effects of membrane-permeable cAMP analogs or cAMP injection. A second kind of test has been suggested by L. K. Kaczmarek (personal communication): If it can be shown that the effect of forskolin is potentiated by phosphodiesterase inhibitors, or that forskolin itself has no effect without concomitant application of a phosphodiesterase inhibitor, then the effect is likely to result from forskolin-dependent activation of adenylate cyclase.

\section{References}

Adams, D. J., S. J. Smith, and S. H. Thompson (1980) Ionic currents in molluscan soma. Annu. Rev. Neurosci. 3: 141-167.

Adams, W., and I. B. Levitan (1982) Intracellular injection of protein kinase inhibitor blocks the serotonin-induced increase in $\mathrm{K}^{+}$conductance in Aplysia neuron R15. Proc. Natl. Acad. Sci. USA 79: 38773880.

Aldenhoff, J., G. Hofmeier, H. D. Lux, and D. Swandulla (1983) Stimulation of a sodium influx by cAMP in Helix neurons. Brain Res. 276: 289-296.

Alkon, D. L., J. Acosta-Urquidi, J. Olds, G. Kuzma, and J. T. Neary (1983) Protein kinase injection reduces voltage-dependent potassium currents. Science 219: 303-306.

Barish, M. E., and S. H. Thompson (1983) Calcium buffering and slow recovery kinetics of calcium-dependent outward current in molluscan neurones. J. Physiol. (Lond.) 337: 201-219.

Bevington, P. R. (1969) Data Reduction and Error Analysis for the Physical Sciences, McGraw-Hill, New York.

Castellucci, V. T., E. R. Kandel, J. H. Schwartz, F. D. Wilson, A. C. Nairn, and P. Greengard (1980) Intracellular injection of the catalytic subunit of cyclic AMP-dependent protcin kinase simulates facilitation of transmitter release underlying behavioral sensitization in Aplysia. Proc. Natl. Acad. Sci. USA 77: 7492-7496.

Connor, J. A. (1977) Time course separation of two inward currents in molluscan neurons. Brain Res. 119: 487-492.

Connor, J. A., and P. Hockberger (1984) A novel membrane sodium current induced by injection of cyclic nucleotides into gastropod neurones. J. Physiol. (Lond.) 354: 139-162.

Coraboeuf, E., and E. Carmeliet (1982) Existence of two transient outward currents in sheep cardiac purkinje fibers. Pfluegers Arch. 392 352-359

DePeyer, J. E., A. B. Cachelin, I. B. Levitan, and H. Reuter (1982) $\mathrm{Ca}^{++}$-activated $\mathrm{K}^{+}$conductance in internally perfused snail neurons is enhanced by protein phosphorylation. Proc. Natl. Acad. Sci. USA 79: 4207-4211.

Deterre, P., D. Paupardin-Tritsh, J. Bockaert, and H. M. Gershenfeld (1982) CAMP-mediated decrease in $\mathrm{K}^{+}$conductance evoked by serotonin and dopamine in the same neuron: $A$ biochemical and physiological single-cell study. Neurobiology 79: 7934-7938.

Drummond, A. H., J. A. Benson, and I. B. Levitan (1980) Serotonininduced hyperpolarization of an identified Aplysia neuron is mediated by cyclic AMP. Proc. Natl. Acad. Sci. USA 78: 5013-5017.

Ewald, D. A., A. Williams, and I. B. Levitan (1985) Modulation of single $\mathrm{Ca}^{++}$-dependent $\mathrm{K}^{+}$-channel activity by protein phosphorylation. Nature 315: 503-506.

Green, D., and R. Gillette (1983) Patch- and voltage-clamp analysis of cyclic AMP-stimulated inward current underlying neurone bursting. Nature 306: 784-785.

Hille, B. (1977) Local anesthetics: Hydrophilic and hydrophobic pathways for the drug-receptor reaction. J. Gen. Physiol. 69: 497-515.
Kaczmarek, L. K., and F. Strumwasser (1984) A voltage clamp analysis of currents underlying cAMP-induced membrane modulation in isolated peptidergic neurons of Aplysia. J. Neurophysiol. 52: 340349.

Kauer, J., and L. Kaczmarek (1985) Peptidergic neurons of Aplysia lose their response to cAMP during a prolonged refractory period. $J$. Neurosci. 5: 1339-1345.

Kennedy, M. B. (1983) Experimental approaches to understanding the role of protein phosphorylation in the regulation of neuronal function. Annu. Rev. Neurosci. 6: 493-525.

MacDermott, A. B., and F. F. Weight (1982) Action potential repolarization may involve a transient $\mathrm{Ca}^{++}$-sensitive outward current in a vertebrate neurone. Nature 300: 185-188.

Marquardt, D. W. (1963) An algorithm for least-squares estimation of nonlinear parameters. J. Soc. Adv. Appl. Math. 11: 431-441.

McHugh, E. M., and R. Mcgee, Jr. (1986) Direct anesthetic-like effects of forskolin on the nicotinic acetylcholine receptors of PC12 cells. J. Biol. Chem. (in press).

Nestler, E. J., and P. Greengard (1983) Protein phosphorylation in the brain. Nature 305: 583-588.

Nestler, E. J., and P. Greengard (1984) Protein Phosphorylation in the Nervous System, Wiley, New York.

Pellmar, T. C. (1981) Ionic mechanisms of a voltage-dependent current elicited by cyclic AMP. Cell. Mol. Neurobiol. 1: 87-97.

Pfeuffer, J., and Metzger, H. (1982) 7-O-Hemisuccinyl-diacetyl forskolin-sepharose: A novel affinity support for purification of adenylate cyclase. FEBS Lett. 146(2): 369-375.

Ram, J. L. (1983) Forskolin activation of an identified peptide-sensitive mononeurone in Aplysia. Br. J. Pharmacol. 79: 631-633.

Salkoff, L. (1983) Drosophila mutants reveal two components of fast transient current. Nature 302: 249-251.

Seamon, K. B., and J. W. Daly (1981) Forskolin: A unique diterpene activator of cyclic AMP-generating systems. J. Cyclic Nucleotide Res. 7(4): 201-224.

Seamon, K. B., W. Padgett, and J. W. Daly (1981) Forskolin: Unique diterpene activator of adenylate cyclase in membranes and in intact cells. Proc. Natl. Acad. Sci. USA 78: 3363-3367.

Seamon, K. B., R. Vaillancourt, M. Edwards, and J. W. Daly (1984) Binding of $\left[{ }^{3} \mathrm{H}\right]$ forskolin to rat brain membranes. Proc. Natl. Acad. Sci. USA 81: 5081-5085.

Shuster, M. J., J. S. Camardo, S. A. Siegelbaum, and E. R. Kandel (1985) Cyclic AMP-dependent protein kinase closes the serotoninsensitive $\mathrm{K}^{+}$channels of Aplysia sensory neurones in cell-free membrane patches. Nature 313: 392-395.

Siegelbaum, S. A., and R. W. Tsien (1980) Calcium-activated transient outward current in calf cardiac Purkinje fibres. J. Physiol. (Lond.) 299: 485-506.

Siegelbaum, S. A., and R. W. Tsien (1983) Modulation of gated ion channels as a mode of transmitter action. TINS 6(8): 307-313.

Siegelbaum, S. A., J. S. Camardo, and E. R. Kandel (1982) Serotonin and cAMP close single $\mathrm{K}^{+}$channels in Aplysia sensory neurones. Nature 299: 413-417.

Strong, J. (1983) Neuromodulation of A-current kinetics in bag cell neurons of Aplysia. Ph.D. disscrtation, Yalc University.

Strong, J. (1984) Modulation of potassium current kinetics in bag cell neurons of Aplysia by an activator of adenylate cyclase. J. Neurosci. 4: 2772-2783.

Strong, J. A., and L. K. Kaczmarek (1986) Multiple components of delayed potassium current in peptidergic neurons of Aplysia: Modulation by an activator of adenylate cyclase. J. Neurosci. 6: 814-822.

Thompson, S. H. (1977) Three pharmacologically distinct potassium channels in molluscan neurons. J. Physiol. (Lond.) 265: 465-488.

Thompson, S. (1982) Aminopyridine block of transient potassium current. J. Gen. Physiol. 80: 1-18.

Walsh, J. P., and J. H. Byrne (1985) Analysis of decreased conductance serotonergic response in Aplysia ink motor neurons. J. Neurophysiol. 53: $590-602$. 